\title{
Resistência antimicrobiana da Salmonella spp. em suínos: Revisão
}

\author{
Antimicrobial resistance of Salmonella spp. in swine: Review \\ Resistencia antimicrobiana de la Salmonella spp. en cerdos: Revisión
}

Thiago Langer Lantmann

ORCID: https://orcid.org/0000-0001-8762-2539 Universidade Federal do Rio Grande do Sul, Brasil E-mail: thiagolantmann@hotmail.com.br

Tainá Simonetti

ORCID: https://orcid.org/0000-0003-1175-9998 Universidade Federal do Rio Grande do Sul, Brasil E-mail: taina_simonetti@hotmail.com

Liris Kindlein

ORCID: https://orcid.org/0000-0002-3925-1128 Universidade Federal do Rio Grande do Sul, Brasil E-mail: liris.kindlein.ufrgs@gmail.com João Roberto Braga de Mello

ORCID: https://orcid.org/0000-0002-7120-7709 Universidade Federal do Rio Grande do Sul, Brasil E-mail: jmello@gabinete.ufrgs.br

\begin{abstract}
Resumo
A suinocultura representa uma atividade muito relevante para o Brasil, gerando empregos, renda e desenvolvimento. Atualmente, o mercado nacional e internacional vem exigindo um status sanitário de rebanho cada vez mais qualificado. Dentro disso, a salmonelose é uma enfermidade que merece destaque. A Salmonella é um agente etiológico de grande envolvimento em surtos alimentares em seres humanos, e vem apresentando um forte aumento no condizente à resistência antimicrobiana devido ao uso indiscriminado de antibióticos em animais de produção e pacientes, tornandose uma ameaça à saúde pública por todo o globo. O surgimento de isolados de Salmonella com tal resistência foi descrito em humanos, alimentos e animais para consumo. Por esse motivo, foi realizada uma revisão de literatura no condizente à Salmonella spp. e sua resistência frente à utilização de antibioticoterapia na suinocultura, com consulta de instruções normativas, teses e artigos científicos de diversas bases de dados, tais como Scielo, ScienceDirect e PubMed. Pôde-se constatar a grande resistência antimicrobiana de Salmonella frente aos inúmeros princípios ativos utilizados na antibioticoterapia na suinocultura ao longo dos anos. Foi constatado também, que para os próximos anos a tendência é da utilização de alternativas à antibióticos, como óleos essenciais, ácidos orgânicos e inorgânicos, entre outros.
\end{abstract}

Palavras-chave: Resistência antimicrobiana; Salmonella spp.; Saúde pública; Suinocultura; Zoonose.

\begin{abstract}
Swine farming represents a very relevant activity for Brazil, generating jobs, income and development. Currently, the national and international market has been demanding an increasingly qualified herd health status. Within this, salmonellosis is a disease that deserves to be highlighted. Salmonella is an etiological agent of great involvement in food outbreaks in humans, and has shown an elevated increase in antimicrobial resistance due to the indiscriminate use of antibiotics in treating livestock and humans, becoming a global threat to public health. The emergence of isolation of Salmonella with such resistance has been described in humans, food and animals for consumption. For this reason, this paper conducted a literature review on Salmonella spp. and its resistance to the use of antibiotic therapy in swine farming, with consultation of normative instructions, dissertations, and scientific articles from several databases such as Scielo, ScienceDirect, and PubMed. It was possible to verify the great antimicrobial resistance of Salmonella against the countless active principles used in antibiotic therapy in swine farming over the years. It was also found that for the upcoming years there is a trend in using alternatives to antibiotics, such as essential oils, organic and inorganic acids, among others.
\end{abstract}

Keywords: Antimicrobial resistance; Public health; Salmonella spp.; Swine farming; Zoonosis.

\section{Resumen}

La porcicultura representa una actividad muy relevante para Brasil, generadora de empleo, renta y desarrollo. En la actualidad, los mercados internacionales y el nacional pasaron a exigir un rebaño cada vez más calificado en estado sanitario. Sobre este tema, la salmonelosis es una enfermedad que merece ser destacada. Salmonella es un agente etiológico de gran implicación en brotes alimentarios en humanos, y ha mostrado un fuerte aumento de la resistencia antimicrobiana debido al uso indiscriminado de antibióticos en animales de producción y en pacientes, convirtiéndose 
en una amenaza para la salud pública en todo el globo. Se ha percibido la aparición de aislamientos de Salmonella con tal resistencia en humanos, alimentos y animales para consumo. Por tal motivo, se realizó una revisión bibliográfica sobre Salmonella spp. y su resistencia al uso de la antibioticoterapia en porcicultura, con consulta de instructivos normativos, tesis y artículos científicos de múltiples bases de datos, como Scielo, ScienceDirect y PubMed. Se pudo comprobar la gran resistencia antimicrobiana de la Salmonella frente a los numerosos principios activos utilizados en la antibioticoterapia en porcinos a lo largo de los años. También se encontró que para los próximos años la tendencia es utilizar alternativas a los antibióticos, como aceites esenciales, ácidos orgánicos e inorgánicos, entre otros.

Palabras clave: Porcicultura; Resistencia antimicrobiana; Salmonella spp.; Salud pública; Zoonosis.

\section{Introdução}

A Salmonella spp. é um importante patógeno zoonótico, além de relacionar-se a uma das principais causas de doenças transmissíveis por alimentos (DTAs) em humanos, tendo diversas fontes de contaminação responsáveis pela ocorrência desta enfermidade. Deste modo, um destaque vem sendo atribuído à espécie suína como um reservatório importante para diversos sorovares de Salmonella e, assim, realçando a veiculação deste microrganismo para o homem através do consumo de seus produtos ou mediante contaminação cruzada para outros alimentos (Brasil, 2021).

Além disso, com o passar dos anos, vêm relatando-se o isolamento de sorovores de Salmonella spp. resistentes a antimicrobianos, sendo este fato relacionado a inúmeros fatores. De acordo com a World Health Organization (2016), a resistência antimicrobiana (RAM) ocorre quando microrganismos sofrem alterações no momento de exposição aos antimicrobianos, tornando medicamentos ineficazes e aumentando o risco de propagação da doença. A utilização exacerbada de antimicrobianos, tanto na área humana quanto na área da medicina veterinária, para fins terapêuticos, profiláticos e promotores de crescimento, vem gerando preocupações e impactando no desenvolvimento de RAM, de maneira a contribuir significativamente para este problema de saúde pública a nível global (Tang, et al., 2017).

Devido a sua relevância como patógeno no âmbito da saúde pública, este microrganismo requer atenção para utilização de medidas específicas, de legislações e de programas de controle que garantam a não comercialização de alimentos que possam vir a apresentar isolamento de Salmonella spp.

\section{Metodologia}

Neste estudo foi realizada uma revisão de literatura (ou revisão narrativa), uma metodologia na qual consiste em realizar uma discussão sobre o material abordado em forma de ensaio teórico, com aprofundamento de sua análise através de relações com produções anteriores, identificando temáticas recorrentes e apontando novas perspectivas.

Utilizou-se como base uma extensa pesquisa bibliográfica em bases de dados científicos confiáveis como: Science Direct, Scientific Electronic Library Online (Scielo), PubMed, bem como Embrapa, NCBI, NTU Scholars, Pubvet, ResearchGate, repositórios de universidades (dissertações e teses) e Google. Foram selecionadas publicações datadas entre os anos de 2010 a 2021 para elaboração de uma revisão visando a resistência antimicrobiana à Salmonella spp. frente à utilização de antibioticoterapia na suinocultura. $\mathrm{O}$ estudo foi realizado nos meses de janeiro de 2022 por meio de pesquisa básica.

A estratégia utilizada nas bases de dados foi o uso dos termos: "antimicrobial resistance", "Salmonella", "swine" no campo correspondente a título, resumo, palavras-chave e somente artigos, abrangendo as publicações abertas no período supracitado. Verificou-se, inicialmente os trabalhos em duplicidade devido a utilização de três bases de dados. Os operadores booleanos "OR" e "AND" foram utilizados a fim de conectar os termos da pesquisa entre si, facilitando a visualização da busca. Após a verificação de compatibilidade das publicações encontradas nas pesquisas, em relação ao assunto abordado, selecionouse 33 publicações para a elaboração do trabalho (Quadro 1). 
Quadro 1. Principais publicações selecionadas e utilizadas para a elaboração da revisão.

\begin{tabular}{|c|c|c|c|}
\hline Autor(es) & Ano & Título & Indexador \\
\hline $\begin{array}{l}\text { Centers for Disease Control } \\
\text { and Prevention }\end{array}$ & 2019 & Antibiotic Resistance Threats in the United States. & Google \\
\hline Cheng et al. & 2019 & $\begin{array}{l}\text { A critical review on antibiotics and hormones in swine } \\
\text { wastewater: Water pollution problems and control } \\
\text { approaches. }\end{array}$ & ScienceDirect \\
\hline De Lange et al. & 2010 & $\begin{array}{l}\text { Strategic use of feed ingredients and feed additives to } \\
\text { stimulate gut health and development in young pigs. }\end{array}$ & ScienceDirect \\
\hline Dowarah et al. & 2017 & $\begin{array}{l}\text { The use of Lactobacillus as an alternative of antibiotic } \\
\text { growth promoters in pigs: A review. }\end{array}$ & ScienceDirect \\
\hline EFSA Journal & 2012 & $\begin{array}{l}\text { Union summary report on antimicrobial resistance in } \\
\text { zoonotic and indicator bacteria from humans, animals and } \\
\text { food in } 2010 \text {. }\end{array}$ & Google \\
\hline Faria & 2013 & $\begin{array}{l}\text { Principais sorotipos de Salmonella enterica isolados em } \\
\text { suínos. }\end{array}$ & Google \\
\hline Faria & 2016 & $\begin{array}{l}\text { Escherichia coli e Salmonella sp. em suiformes nativos } \\
\text { exóticos assintomáticos em criações comerciais do estado de } \\
\text { goiás. }\end{array}$ & Repositório UFG \\
\hline Filho et al. & 2014 & $\begin{array}{l}\text { Investigation of Salmonella spp. in backyard chickens } \\
\text { (Gallus gallus domesticus) and eggs sold in free markets in } \\
\text { the city of Fortaleza. }\end{array}$ & ResearchGate \\
\hline Forstinus et al. & 2015 & Epidemiology of Salmonella and Salmonellosis. & ResearchGate \\
\hline Gozi & 2016 & $\begin{array}{l}\text { Perfil de resistência à antimicrobianos de Aeromonas sp. e } \\
\text { Streptococcus } s p \text {. isolados de tilápia-do-Nilo e detecção dos } \\
\text { genes envolvidos na resistência à tetraciclina. }\end{array}$ & Repositório UNES \\
\hline Kich et al. & 2017 & $\begin{array}{l}\text { Salmonelose clínica em suínos no Brasil: diagnóstico e } \\
\text { controle. }\end{array}$ & Embrapa \\
\hline Kim \& Isaacson. & 2017 & Salmonella in Swine: Microbiota Interactions. & PubMed \\
\hline Liao \& Nyachoti. & 2017 & $\begin{array}{l}\text { Using probiotics to improve swine gut health and nutrient } \\
\text { utilization. }\end{array}$ & ScienceDirect \\
\hline Lima et al. & 2016 & $\begin{array}{l}\text { Sorovares e perfil de suscetibilidade a antimicrobianos em } \\
\text { Salmonella spp. isoladas de produtos de origem suína. }\end{array}$ & Scielo \\
\hline Lopes & 2019 & $\begin{array}{l}\text { Efeito osteogênico do compósito produzido com cerâmica } \\
\text { de beta tricálcio fosfato, polímeros [pcl e plga] e } \beta \text { - } \\
\text { ciclodextrina, associado à doxiciclina, no modelo de reparo } \\
\text { ósseo alveolar em ratos. }\end{array}$ & Repositório UFMG \\
\hline Lysnyansky \& Ayling. & 2016 & $\begin{array}{l}\text { Mycoplasma bovis: Mechanisms of Resistance and Trends } \\
\text { in Antimicrobial Susceptibility. }\end{array}$ & PubMed \\
\hline Mendonça & 2016 & $\begin{array}{l}\text { Características de virulência, resistência e diversidade } \\
\text { genética de sorovares de Salmonella com impacto na saúde } \\
\text { pública, isolados de frangos de corte no Brasil. }\end{array}$ & Repositório UFU \\
\hline Moreira & 2012 & $\begin{array}{l}\text { Estudo sobre Salmonella sp. e seus mecanismos de } \\
\text { resistência a antibióticos. }\end{array}$ & Repositório UFG \\
\hline Oliveira, et al. & 2020 & $\begin{array}{l}\text { Sobrevivência e perfil de resistência a antimicrobianos de } \\
\text { isolados de Salmonella sp. em dejeto suíno armazenado. }\end{array}$ & Pubvet \\
\hline Oliver \& Wells. & 2015 & $\begin{array}{l}\text { Lysozyme as an alternative to growth promoting antibiotics } \\
\text { in swine production. }\end{array}$ & PubMed \\
\hline Omonijo, et al. & 2018 & $\begin{array}{l}\text { Essential oils as alternatives to antibiotics in swine } \\
\text { production. }\end{array}$ & PubMed \\
\hline Quadros & 2018 & $\begin{array}{l}\text { Salmonella spp. isoladas em abatedouro frigorífico de } \\
\text { suínos: resistência a sanitizantes e antimicrobianos. }\end{array}$ & Repositório UPF \\
\hline Rodrigues, et al. & 2014 & $\begin{array}{l}\text { Relatório anual de atividades do Laboratório de Referência } \\
\text { Nacional de Enteroinfecções Bacterianas. }\end{array}$ & ResearchGate \\
\hline Ryan, et al. & 2017 & $\begin{array}{l}\text { Evaluation of the Complex Nomenclature of the Clinically } \\
\text { and Veterinary Significant Pathogen Salmonella. }\end{array}$ & PubMed \\
\hline Santana, et al. & 2021 & Febre tifoide: revisão para a prática clínica. & Google \\
\hline
\end{tabular}




\begin{tabular}{|c|c|l|c|}
\hline Silva, et al. & 2018 & $\begin{array}{l}\text { Salmonella spp. Um Agente Patogênico Veiculado em } \\
\text { Alimentos. }\end{array}$ & Google \\
\hline Subramaniam \& Kim. & 2015 & Clays as dietary supplements for swine: A review. & PubMed \\
\hline Suiryanrayna, \& Ramana. & 2015 & A review of the effects of dietary organic acids fed to swine. & NCBI \\
\hline Suo, et al. & 2010 & $\begin{array}{l}\text { A multiplex real-time polymerase chain reaction for } \\
\text { simultaneous detection of Salmonella sp., Escherichia coli } \\
\text { O157 and Listeria monocytogenes in meat products. }\end{array}$ & PubMed \\
\hline Turci, et al. & 2013 & $\begin{array}{l}\text { Incidência de Salmonella sp. em carne de suíno } \\
\text { comercializada no município de Umuarama - PR - Brasil. }\end{array}$ & Google \\
\hline Wang, et al. & 2010 & $\begin{array}{l}\text { Antibiotic resistance, integrons and Salmonella genomic } \\
\text { island 1 among Salmonella Schwarzengrund in broiler } \\
\text { chicken and pig. }\end{array}$ & $\begin{array}{l}\text { Broth microdilution protocol for minimum inhibitory } \\
\text { concentration (MIC) determinations of the intracellular } \\
\text { salmonid pathogen Piscirickettsia salmonis to florfenicol } \\
\text { and oxytetracycline. }\end{array}$ \\
\hline Yáñez, et al. & 2012 & $\begin{array}{l}\text { Mutations in gyrase and topoisomerase genes associated } \\
\text { with fluoroquinolone resistance in Salmonella serovars from } \\
\text { retail meats. }\end{array}$ & PubMed \\
\hline Yang, et al. & Google \\
\hline
\end{tabular}

Fonte: Autores (2022).

\section{Resultados e Discussão}

\subsection{Salmonella spp.}

O gênero Salmonella spp. pertence à família Enterobacteriaceae e é o agente causador da salmonelose, uma das doenças entéricas mais importantes em suínos. Ela divide-se em duas espécies: Salmonella bongori e Salmonella enterica, sendo esta última subdividida em seis subespécies (enterica, salamae, arizonae, diarizonae, houtenae e indica), possuindo mais de 2.600 sorovares. Ela possui como seu habitat natural o trato intestinal de humanos e de outros animais, apresentando a maioria dos patógenos humanos na subespécie Salmonella enterica grupo enterica (Forstinus, et al., 2015; Mendonça, 2016).

Sua classificação em sorotipos está relacionada à algumas características, como seus antígenos somáticos de parede de natureza lipopolissacarídea, os flagelares de natureza proteica e os capsulares relacionados à virulência (Faria, 2016).

Em relação à gama de hospedeiros, mais precisamente a respeito da $S$. enterica, pode ser dividida em três categorias gerais: sorovares de ampla gama de hospedeiros, sorovares restritos a hospedeiros e sorovares específicos de hospedeiros (Quadro 2). Cabe destacar o sorovar Choleraesuis, sorovar específico para suínos e geralmente responsável por ocasionar doença grave, invasiva e septicêmica para os animais (Kim \& Isaacson, 2016; Kich, 2017). 
Quadro 2. Exemplos de sorovares de Salmonella enterica, seus hospedeiros e doenças causadas.

\begin{tabular}{|c|c|c|}
\hline Sorovar & Hospedeiro & Doença zoonótica/diarreia \\
\hline \multicolumn{3}{|c|}{ Sorovares específicos ao hospedeiro } \\
\hline Choleraesuis & Porco & Sim \\
\hline Dublin & Gado & Sim \\
\hline \multicolumn{3}{|c|}{ Sorovares restritos ao hospedeiro } \\
\hline Typhi & Humano & Não \\
\hline Paratyphi A & Humano & Não \\
\hline Paratyphi C & Humano & Não \\
\hline Sendai & Humano & Não \\
\hline Abortusovis & Ovelha & Não \\
\hline Gallinarum & Galinha & Não \\
\hline Typhisuis & Porco & Não \\
\hline Abortusequi & Cavalo & Não \\
\hline \multicolumn{3}{|c|}{ Sorovares de ampla gama de hospedeiros - os 10 mais comuns ${ }^{\mathrm{a}}$} \\
\hline Enteritidis & Animais de fazenda & Sim \\
\hline Typhimurium & Animais de fazenda & Sim \\
\hline Newport & Animais de fazenda & Sim \\
\hline Javiana & Animais de fazenda & Sim \\
\hline 14,[5].12:i:- & Animais de fazenda & Sim \\
\hline Montevideo & Animais de fazenda & Sim \\
\hline Heidelberg & Animais de fazenda & Sim \\
\hline Munchen & Animais de fazenda & Sim \\
\hline Infantis & Animais de fazenda & Sim \\
\hline Branderup & Animais de fazenda & Sim \\
\hline
\end{tabular}

${ }^{a}$ http://www.cdc.gov/ncezid/dfwed/pdfs/salmonella-annual-report-2011-508c.pdf. Fonte: Adaptado de Kim \& Isaacson (2016).

As bactérias deste gênero apresentam-se como gram-negativas, não formadoras de esporos, anaeróbias facultativas e não fermentam lactose (porém, muitas cepas podem adquirir essa característica por meio de transferência plasmidial). Suas características de margem de temperatura para multiplicação se encontram entre 5 a $46^{\circ} \mathrm{C}$, sendo sua temperatura ótima de $37^{\circ} \mathrm{C}$, enquanto o seu valor de pH encontra-se na faixa de 3,8 a 9,5, com valor ótimo entre 6,6 e 8,2 (Ryan, et al., 2017; Quadros, 2018; Silva, et al., 2018).

Assim como em outros bacilos gram-negativos, as salmonelas têm em sua parede celular um revestimento de camada complexa de lipopolissacarídeo, além de flagelos, fímbrias, e algumas proteínas da membrana externa que atuam na adesão e/ou invasão do epitélio do trato intestinal. Sendo que esta camada lipossacarídica exerce uma função de barreira hidrofóbica, atribuindo características relevantes de resistência à dessecação e ao congelamento, por exemplo, fazendo também, com que a entrada de substâncias nocivas, como sais biliares, enzimas digestivas e alguns antibióticos seja restringida. Além disso, facilita a evasão da bactéria no sistema imunológico do hospedeiro (Suo, et al., 2010; Mendonça, 2016).

\subsubsection{Salmonelose em humanos}

Em humanos, a Salmonella pode causar diferentes doenças dependendo do sorotipo em questão, sendo elas: salmonelose não tifoide e febre tifoide (Brasil, 2021). 
A salmonelose não tifoide é uma doença que acomete os seres humanos através do consumo de alimentos, de origem animal ou não, ou água contaminadas pela bactéria, caracterizando uma toxinfecção. Além desta transmissão via alimentar, existe a possibilidade de ocorrência devido a erros de procedimento em abatedouros-frigoríficos, como contaminação cruzada pelo excesso de manipulação durante o beneficiamento da carne ou contato de carne processada com carne crua. A gravidade da enfermidade varia conforme fatores relacionados a resposta do hospedeiro ao patógeno. A maioria dos casos de salmonelose não tifoide, em humanos, ocasiona sintomas de vômito, dores abdominais, febre, cansaço, perda de apetite, sangue nas fezes e diarreia, que geralmente surgem entre seis e 72 horas após o contato com o agente, costumando perdurar entre dois a sete dias (Turci, et al., 2013; Brasil, 2021).

A febre tifoide, por sua vez, figura como relevante causa de morbidade e é altamente incidente em países em desenvolvimento estando comumente relacionada a viagens, apesar de ser evitável através da adoção de medidas preventivas como a introdução da vacina conjugada (Santana, et al., 2021). Ademais, em casos atípicos, pode ocorrer quadros de desidratação e, se não for realizado o tratamento inicial, o quadro pode se agravar podendo levar ao óbito. A doença ocorre de maneira mais agressiva em crianças, idosos e gestantes devido a imunossupressão, assim como em transplantados ou portadores de Aids/HIV (Turci, et al., 2013; Brasil, 2021).

Segundo o Centers for Disease Control, há uma estimativa de que a S. enterica é o agente causador de mais de 1,2 milhões de casos por ano das doenças transmitidas através dos alimentos nos Estados Unidos (CDC, 2019). E, conforme Kim e Isaacson (2016), os prejuízos econômicos neste mesmo país em razão da Salmonelose excedem, em média, 3,5 bilhões de dólares anualmente.

De acordo com Rodrigues et al. (2014), Salmonella ser. typhimurium é considerado um dos principais sorovares relacionados a casos de salmonelose tanto em animais quanto em seres humanos, destacando-se no Brasil, devido sua presença na suinocultura e alimentos para consumo humano.

\subsubsection{Salmonelose em suínos}

As infecções por S. enterica normalmente ocorrem por via fecal-oral. A transmissão bacteriana dentro do lote é de extrema complexidade, visto que existem diversas fontes de infecção e momentos em que as bactérias são eliminadas. Dentre as fontes, destacam-se: excreção de fezes contaminadas pelos animais, falha de protocolo ou ausência de limpeza e desinfecção, e vazio sanitário inadequado, vetores (roedores e moscas), ração e água contaminados, assim como biosseguridade negligenciada. O momento crítico da transmissão pelo animal ocorre no estado de portador assintomático, onde há a possibilidade de reativar a excreção de Salmonella, especialmente em momentos de estresse, como transporte e mistura de animais (Kich, et al., 2017).

Kich et al. (2017) afirmam que a salmonelose em suínos atinge animais entre cinco semanas e quatro meses de vida, nas fases de creche, crescimento e início da terminação, podendo ocorrer sinais clínicos relacionados à septicemia (sorovar choleraesuis) ou à diarreia/enterocolite (sorovar typhimurium). Quando ingerida, a Salmonella choleraesuis ultrapassa a barreira intestinal e alcança tecidos linfoides secundários originando uma septicemia. Já em relação ao sorovar Typhimurium, o mesmo circula por hospedeiros distintos e coloniza o sistema digestório levando a um agravamento entérico. Além desses, há outros sorovares capazes de causar danos na produção animal, embora os mesmos não originem quadros clínicos em suínos.

Os quadros que cursam com diarreia caracterizam-se pela ocorrência de sinais clínicos como febre, perda de apetite e refugagem, podendo levar o animal a óbito. Além disso, a diarreia presente neste quadro é caracterizada por ser efusiva, inflamatória e cursa de modo intermitente, no entanto, raramente há presença de sangue nas mesmas. Por outro lado, os quadros com cenários septicêmicos apresentam uma mortalidade súbita mesclados a estados febris e cianose nas extremidades. Nestes casos, também ocorre perda de apetite e refugagem acompanhadas por sinais de fraqueza, além de dificuldade de locomoção e tendência dos animais de se amontoarem (Kich, et al., 2017). 
Para um correto diagnóstico, é necessário considerar a sintomatologia clínica e suas lesões características no momento da necropsia. Além do mais, para a confirmação do mesmo, pode ser realizado exames bacteriológicos, Reação em Cadeia da Polimerase (PCR), histopatologia e imunohistoquímica. Condizente à detecção do agente, realiza-se o isolamento microbiológico seguido de sorologia através da técnica de aglutinação ou, em programas intensivos de controle de Salmonella, como também pode ser realizado o monitoramento sorológico por teste imunoenzimático (ELISA) (Kich, et al., 2017).

O tratamento para salmonelose em suínos se dá basicamente através de antimicrobianos, e é a partir do correto diagnóstico que se obtém maior eficiência e precisão no tratamento. Visto que os isolados de Salmonella apresentam alta variabilidade em seus perfis frente aos princípios ativos, tanto de sensibilidade quanto de resistência, a realização de um antibiograma se torna imprescindível para que se tome a melhor decisão, a fim de se obter a melhor escolha do medicamento (Kich, et al., 2017).

\subsection{Antibioticoterapia em suínos frente à Salmonella spp.}

Como escolha do tratamento de infecções por Salmonella, a ampicilina, sulfametoxazol-trimetoprim e cloranfenicol foram utilizadas como princípios ativos durante anos. Desse modo, as taxas de resistência a esses agentes foram se tornando crescentes, e assim, reduziram significativamente sua eficácia. Como resposta, passou-se a administrar fluoroquinolonas e cefalosporinas de amplo espectro (Lima, et al., 2016). Atualmente, a seleção gradativa de Salmonella resistente a essas classes de antimicrobianos vem sendo um importante problema de saúde pública, de modo a impactar no tratamento e na prevenção de doenças infecciosas em humanos e animais (EFSA, 2012).

Em estudo realizado por Kich et al. (2017), os princípios ativos que apresentaram sensibilidade acima de $80 \%$, frente aos 112 isolados de Salmonella oriundos de casos clínicos de suínos no Brasil foram: fosfomicina, lincomicina+espectinomicina e norfloxacina. Entre 70 e $80 \%$ de sensibilidade em ordem decrescente, foram: ceftiofur, colistina e sulfametoxazol+trimetoprim. E por fim, os princípios ativos que apresentaram maior resistência foram, em ordem decrescente: tetraciclina, doxiciclina, gentamicina, estreptomicina e florfenicol.

De acordo com Oliveira et al. (2020), após isolar amostras de Salmonella spp. de sistemas de armazenamento de dejetos suínos observou-se, também, uma alta resistência à tetraciclina, representando uma taxa de 59\%. Tamanha resistência à tetraciclina é um resultado plausível, pois tal fármaco é um dos antimicrobianos mais antigos utilizados, tanto para o tratamento quanto para a promoção de crescimento (com uso em subdosagens). Todavia, no Brasil, as tetraciclinas foram banidas em 1998 como aditivos alimentares em rações de animais, estando liberadas apenas para a utilização de forma terapêutica (Lima, et al., 2016).

Os mecanismos de resistência à tetraciclina pela bactéria, ocorrem através do efluxo das moléculas de tetraciclina, de proteção ribossômica e da inativação da droga (Gozi, 2016). A resistência ocorre devido a proteínas denominadas Tet (Tet A, B, C e D) que, após formadas, encontram-se na membrana citoplasmática. Segundo Moreira (2016), existem mais de 35 diferentes genes que codificam resistência a tetraciclina, relacionados a bombas de efluxo associadas à membrana, capazes de exportar tetraciclina, oxitetraciclina e doxiciclina, enquanto tet $B$, além destes, é capaz de exportar também a minociclina. Ainda afirmam que os genes tetA, tetB têm sido encontrados em alta frequência em Salmonella.

Em relação à doxiciclina, pertencente à classe das tetraciclinas, em estudo realizado por Lima et al. (2016) foi observado $36 \%$ dos isolados de Salmonella spp. resistentes a este princípio ativo, que por sua vez tem como mecanismo de ação a inibição da síntese de proteínas bacterianas via porção 30S dos ribossomos. Sua propriedade lipossolúvel facilita a sua difusão através da membrana celular dos microrganismos susceptíveis, permitindo sua ligação à subunidade $30 \mathrm{~S}$ do ribossomo, inibindo a formação do complexo t-RNA-aminoacil-RNAmribossomo e impedindo, consequentemente, a translação bacteriana (Lopes, 2019). 
A alta taxa de resistência de gentamicina encontrada por Kich et al. (2017) vai de encontro com os achados no trabalho realizado por Machado et al. (2020), onde 69,56\% dos isolados foram resistentes à gentamicina. Tais dados demonstram que a Salmonella e seus genes de resistência seguem amplamente presentes em populações animais e humanas.

Para a estreptomicina, a alta taxa de resistência também ocorreu em outros estudos. Segundo Machado et al. (2020), a taxa de resistência observada foi de $65,21 \%$ dos isolados. Corroborando a isso, em trabalho de Filho (2014), 70\% das amostras coletadas foram resistentes para o princípio ativo supracitado.

Os aminoglicosídeos em questão (gentamicina e estreptomicina) possuem mecanismo de ação relacionado à alteração da função dos ribossomos bacterianos, pela ligação à fração 30S dos ribossomos, inibindo a síntese proteica ou produzindo proteínas 46 defeituosas. Já, no condizente aos mecanismos de resistência, são três as principais consequências: diminuição de permeabilidade celular à droga, alteração dos sítios de ligação no ribossomo (ambos mediados por mutação) e modificação enzimática do antibiótico (mediado por plasmídeos) (Moreira, 2016).

No condizente à utilização de cloranfenicol, sabe-se que o uso veterinário no país foi proibido em 2003 pelo Ministério da Agricultura, Pecuária e Abastecimento (MAPA) (Brasil, 2003), e desde então a utilização de florfenicol, seu análogo fluorado, tem sido amplamente presente na medicina veterinária. Deste modo, tal princípio ativo segue sendo responsável por ocasionar alta pressão de resistência frente a essa classe de antibióticos. Em conformidade, Quadros (2018) identificou a presença de Salmonella spp. em diferentes pontos de um abatedouro-frigorífico de suínos, e foi observada uma frequência de $36 \%$ de resistência ao cloranfenicol frente aos isolados.

Este princípio ativo tem como mecanismo de ação a inibição da síntese proteica da bactéria (ação bacteriostática), de modo que a droga se fixa na fração 50S do ribossomo inibindo a ação da enzima peptidiltransferase (Yáñez, et al., 2014; Lysnyansky \& Ayling, 2016). Sua resistência é mediada principalmente por genes localizados em plasmídeos que codificam a produção de enzimas, denominadas cloranfenicol-acetiltransferases, que inativam o composto (Moreira, 2016).

\subsection{Mecanismos de resistência a antibióticos}

As intervenções ocasionadas pelo uso dos antibióticos podem ocorrer no nível da parede celular, membrana citoplasmática, ribossomos, DNA e metabolismo intermediário das células bacterianas. Atrelado a isso, existem mecanismos de resistência por parte das bactérias, os quais podem ocorrer basicamente por dois processos: mutação ou aquisição de elementos genéticos (Gozi, 2016).

A mutação espontânea e seleção ocorre quando bactérias que transportam mutação no material genético sobrevivem ao uso da droga caso confiram resistência, enquanto as sensíveis são eliminadas. Assim, as células resistentes transferem essa característica as células-filhas, caracterizando a evolução ou transmissão vertical. Tal processo pode ocorrer por diversos mecanismos, como: destruição ou inativação enzimática da droga, bloqueio da entrada no sítio-alvo, alteração no sítio-alvo, efluxo e ejeção do antibiótico (Moreira, 2012).

No tocante ao gênero Salmonella, cabe destacar as mutações pontuais no QRDR (Região Determinante de Resistência a Quinolona), que implicam em grandes questões na saúde pública (Wang, et al., 2010). As fluoroquinolonas e quinolonas possuem como alvo a DNA girase e topoisomerase IV que, por sua vez, são codificadas de forma respectiva pelos genes gyrA, $\operatorname{gyr} \mathrm{B}, \operatorname{par} \mathrm{C}$ e $\operatorname{par} \mathrm{E}$. Dessa forma, dados da literatura demonstraram que as mutações nos genes $\operatorname{gyr} \mathrm{A}, \operatorname{par} \mathrm{C}$ e $\operatorname{par} \mathrm{E}$ originaram altos níveis de resistência quanto ao uso de fluoroquinolonas em diferentes sorovares de Salmonella isolados de carnes de bovinos, aves e cordeiros em comercialização na China (Yang, et al., 2012).

O segundo mecanismo ocorre através da resistência mediada por aquisição de elementos genéticos, que pode ocorrer por integrons, plasmídeos e transposons. A variabilidade genética em Salmonella spp. é responsável pela alteração fisiológica das células e genes de resistência a antimicrobianos, conferindo proteção ao patógeno em questão. Esse mecanismo tem seu 
funcionamento através de codificação de estruturas como os lipopolissacarídeos, flagelos e fímbrias, bem como a expressão de genes de virulência (Gozi, 2016). Desse modo, a transferência gênica ocorre horizontalmente através dos processos de transformação, conjugação ou transdução, onde as bactérias podem adquirir e incorporar aos seus materiais genéticos genes de resistência carreados por elementos móveis de transferência como é o caso dos plasmídeos, transposons e/ou bacteriófagos (vírus especializados em infectar células bacterianas) (Moreira, 2012). Segundo Gozi (2016), as bactérias ainda podem permutar simultaneamente genes de resistência a diversos antibióticos, estabelecendo o fenômeno da multirresistência.

\subsection{Alternativas frente à utilização de antibióticos}

Nos últimos anos, pesquisas têm enfatizado o conhecimento e desenvolvimento de alternativas à antibióticos a fim de garantir avanços na suinocultura (Subramaniam \& Kim, 2015; Omonijo, et al., 2018). Desse modo, espera-se que tais alternativas de antibióticos possam surgir efeito em diversos aspectos, como: aumento da resposta imunológica dos suínos, redução da carga de patógenos na microbiota intestinal, estimulação do estabelecimento de micróbios intestinais benéficos e na estimulação da função digestiva de suínos (De Lange, et al., 2010). Com base em estudo realizado por Cheng et al. (2019), as alternativas mais promissoras são os óleos essenciais, as enzimas, os ácidos orgânicos, os prebióticos e os probióticos. No Quadro 3, estão descritas as características e principais funções dessas alternativas de antibióticos.

Quadro 3. Características e principais funções das alternativas à utilização de antibióticos .

\begin{tabular}{|c|c|c|}
\hline $\begin{array}{l}\text { Alternativas } \\
\text { promissoras }\end{array}$ & Características & Principais funções \\
\hline $\begin{array}{l}\text { Óleos } \\
\text { essenciais }\end{array}$ & $\begin{array}{l}\text { Os óleos essenciais têm propriedades } \\
\text { antimicrobianas, anti-inflamatórias, antioxidantes } \\
\text { e coccidiostáticas }\end{array}$ & $\begin{array}{l}\text { 1) Melhorar a digestibilidade e a imunidade; } 2 \text { ) Promoção da saúde } \\
\text { intestinal, minimizando o efeito das bactérias patogênicas; e 3) } \\
\text { Controle da inflamação, estresse oxidativo, microbiota, } \\
\text { quimiossensibilidade intestinal e detecção de quorum sensing } \\
\text { (QS), para gerar melhor desempenho de produção de odor animal } \\
\text { e emissão de amônia. }\end{array}$ \\
\hline $\begin{array}{l}\text { Ácidos } \\
\text { orgânicos } \quad \text { e } \\
\text { inorgânicos }\end{array}$ & $\begin{array}{l}\text { Os ácidos orgânicos e inorgânicos podem ser } \\
\text { bacteriostáticos e bactericidas e essas ações } \\
\text { dependem dos níveis de sua inclusão }\end{array}$ & $\begin{array}{l}\text { 1) Diminuindo o pH da digesta no estômago em particular e } \\
\text { auxiliando na digestão de proteínas; 2) Reduzir a competição } \\
\text { microbiana com o porco por nutrientes; 3) Estimular a produção e } \\
\text { atividade de enzimas (pancreáticas) no intestino delgado; 4) } \\
\text { Fornecimento de nutrientes preferidos pelo tecido intestinal para } \\
\text { melhorar a integridade e função da mucosa; e 5) estimulação da } \\
\text { secreção de enzimas pancreáticas. }\end{array}$ \\
\hline Enzimas & $\begin{array}{l}\text { As enzimas podem quebrar proteínas, gorduras e } \\
\text { carboidratos por meio de proteases, lipases e várias } \\
\text { carboidrases, fazendo com que sejam mais bem } \\
\text { digeridos e absorvidos como fontes de energia }\end{array}$ & $\begin{array}{l}\text { 1) Melhorar a utilização de nutrientes, saúde intestinal, saúde } \\
\text { gastrointestinal e perfil metabólico; 2) Minimizando a proliferação } \\
\text { de bactérias patogênicas; e 3) Alterar a ecologia das bactérias } \\
\text { gastrointestinais dos suínos. }\end{array}$ \\
\hline Probióticos & $\begin{array}{l}\text { Os probióticos são projetados para estimular certas } \\
\text { cepas benignas ou espécies de bactérias no } \\
\text { intestino em detrimento de outras menos } \\
\text { desejáveis }\end{array}$ & $\begin{array}{l}\text { 1) Estimular o desenvolvimento de uma microbiota saudável com } \\
\text { predominância de bactérias benéficas; 2) Prevenir a colonização } \\
\text { de patógenos entéricos; 3) Aumentar a capacidade digestiva e } \\
\text { diminuir o pH; 4) Melhorar a imunidade da mucosa; e 5) Melhorar } \\
\text { a maturação e integridade do tecido intestinal }\end{array}$ \\
\hline Prebióticos & $\begin{array}{l}\text { Os prebióticos são ingredientes alimentares não } \\
\text { digeríveis que alteram a composição ou o } \\
\text { metabolismo da microbiota intestinal de forma } \\
\text { benéfica. Eles são mais baratos, menos arriscados } \\
\text { e mais fáceis de serem manuseados e incorporados } \\
\text { às dietas do que os probióticos }\end{array}$ & $\begin{array}{l}\text { 1) Reduzir a carga de bactérias no intestino do porco; 2) Reduzir a } \\
\text { inflamação quando suplementado com dietas para suínos; 3) } \\
\text { Melhorar a resistência à colonização bacteriana; e 4) Aumentar a } \\
\text { função de barreira intestinal contra patógenos invasores. }\end{array}$ \\
\hline
\end{tabular}

a(De Lange, et al., 2010; Oliver \& Wells, 2015; Subramaniam \& Kim, 2015; Suiryanrayna \& Ramana, 2015; Dowarah, et al., 2017; Liao \& Nyachoti, 2017; Omonijo, et al., 2018). Fonte: adaptado de Cheng et al. (2019).

Segundo os estudos, todas as alternativas têm potencial para melhorar o desempenho dos suínos. Porém, ainda são necessários mais estudos a fim de adquirir maiores conhecimentos a respeito desse assunto, seja nos modos de ação dessas 
alternativas, sinergia entre eles, dos seus efeitos sobre o crescimento dos animais e até mesmo do impacto financeiro de seu(s) uso.

\section{Considerações Finais}

Sabe-se que o aumento perante a resistência antimicrobiana está relacionado ao uso indiscriminado de antibióticos nos mais diversos setores das competências de medicina humana e veterinária. E assim, gerando enorme impacto na saúde humana e na economia ao redor do mundo.

É necessário a garantia de vigilância adequada com relação ao avanço da resistência antimicrobiana deste grupo bacteriano. Para isso, todos os setores públicos e privados, governamentais e não governamentais, devem implementar estratégias de controle, além de aprimorar as já existentes. A utilização responsável de antimicrobianos e a busca por agentes resistentes em condições alternativas, baseando-se na compreensão dos mecanismos de resistência destes microrganismos, constituem medidas eficazes para o controle e prevenção destes.

Ainda, deve-se ressaltar a importância da atuação do médico veterinário em termos de sua responsabilidade perante toda cadeia de produção de alimentos de origem animal. Tendo como principal objetivo controlar os perigos químicos e biológicos, fornecendo um produto de qualidade e inocuidade dentro dos padrões exigidos por lei.

Sendo assim, pesquisas constantes a respeito de potenciais alternativas aos antibióticos na suinocultura devem ser enfatizadas.

\section{Referências}

Brasil. (2003). Ministério da Agricultura Pecuária e Abastecimento. Instrução normativa n. ${ }^{\circ} 9$ de 27 de junho de 2003 . Proíbe a fabricação, a manipulação, o fracionamento, a comercialização, a importação e o uso dos princípios ativos cloranfenicol e nitrofuranos e os produtos que contenham estes princípios ativos, para uso veterinário e suscetível de emprego na alimentação de todos os animais e insetos. Diário Oficial da União, Brasília, DF, Seção 1, p. 5.

Brasil. (2021). Ministério da Saúde. Governo Federal. Salmonella (Salmonelose): o que é, causas, tratamento e prevenção. https://www.gov.br/saude/ptbr/assuntos/saude-de-a-a-z/s/salmonella-salmonelose

CDC - Centers for Disease Control and Prevention. (2019). Antibiotic Resistance Threats in the United States, 2019. Atlanta, USA.

Cheng, D., Ngo, H. H., Guo, W., Chang, S. W., Nguyen, D. D., Liu, Y., Wei, Q., Wei, D. (2019). A critical review on antibiotics and hormones in swine wastewater: Water pollution problems and control approaches. Journal of Hazardous Materials, 387, 121682. https://doi.org/10.1016/j.jhazmat.2019.121682

De Lange, C., Pluske, J., Gong, J. \& Nyachoti, C. (2010). Strategic use of feed ingredients and feed additives to stimulate gut health and development in young pigs. Livestock Science. 134 (1-3), 124-134.

Dowarah, R., Verma, A. K., \& Agarwal, N. (2017). The use of Lactobacillus as an alternative of antibiotic growth promoters in pigs: A review. Animal Nutrition, $3(1), 1-6$.

EFSA. (2012). Union summary report on antimicrobial resistance in zoonotic and indicator bacteria from humans, animals and food in 2010. EFSA Journal, 10, 2598 .

Faria, A. M. (2013). Principais sorotipos de Salmonella enterica isolados em suínos.

Faria, A. M. (2016). Escherichia coli e Salmonella sp. Em suiformes nativos exóticos assintomáticos em criações comerciais do estado de goiás. Tese de doutorado, Universidade Federal de Goiás, Goiânia, GO, Brasil.

Filho, V. J. R. G., Teixeira, R. S., Lopes, E. S., Albuquerque, Á. H., Lima, S. V. G., Horn, R., Rocha-e-Silva, R. C. \& Cardoso, W. M. (2014) Investigation of Salmonella spp. in backyard chickens (Gallus gallus domesticus) and eggs sold in free markets in the city of Fortaleza, Ceará. Semina: Ciências Agrárias, Londrina, 35 (4), 1855-1864.

Forstinus, N. O., Dickson, D. I. \& Chinyere, A. Q. (2015). Epidemiology of Salmonella and Salmonellosis. International Letters of Natural Sciences. 47, 54-73.

Gozi, K. S. (2016). Perfil de resistência à antimicrobianos de Aeromonas sp. e Streptococcus sp. isolados de tilápia-do-Nilo e detecção dos genes envolvidos na resistência à tetraciclina. Dissertação de mestrado, Centro de Aquicultura, Universidade Estadual Paulista, Jaboticabal, São Paulo, SP, Brasil.

Kich, J. D.; Menegguzzi, M., \& Reichen, C. (2017). Salmonelose clínica em suínos no Brasil: diagnóstico e controle. In: Anais do 10 Simpósio Internacional de Suinocultura (p. 153-166).

Kim, H. B., \& Isaacson, R. E. (2017). Salmonella in Swine: Microbiota Interactions. Annual Review of Animal Biosciences, 5(1), 43-63. 
Liao, S. F., \& Nyachoti, M. (2017). Using probiotics to improve swine gut health and nutrient utilization. Animal Nutrition, 3(4), $331-343$.

Lima, A. L., Rodrigues, D. P., Araújo, M. S., Reis, E. M. F., Festivo, M. L., Rodrigues, E. C. P. \& Lázaro, N. S. (2016). Sorovares e perfil de suscetibilidade a antimicrobianos em Salmonella spp. isoladas de produtos de origem suína. Arquivo Brasileiro de Medicina Veterinária e Zootecnia, 68 (1), $39-47$.

Lopes, B. S. B. (2019). Efeito osteogênico do compósito produzido com cerâmica de beta tricálcio fosfato, polímeros [pcl e plga] e $\beta$-ciclodextrina, associado à doxiciclina, no modelo de reparo ósseo alveolar em ratos. 124f. Dissertação de mestrado, Universidade Federal de Minas Gerais, MG, Brasil.

Lysnyansky, I., \& Ayling, R. D. (2016). Mycoplasma bovis: Mechanisms of Resistance and Trends in Antimicrobial Susceptibility. Frontiers in Microbiology, 7.

Mendonça, E. P. (2016). Características de virulência, resistência e diversidade genética de sorovares de Salmonella com impacto na saúde pública, isolados de frangos de corte no Brasil. Tese de doutorado. Universidade Federal de Uberlândia, Programa de Pós-Graduação em Ciências Veterinárias.

Moreira, N. M. (2012). Estudo sobre Salmonella sp. e seus mecanismos de resistência a antibióticos. Mestrado. Programa de Pós-Graduação em Ciência Animal da Escola de Veterinária e Zootecnia da Universidade Federal de Goiás.

Oliveira, A. D., Mansson, M. A. M., Vieira, T. R. \& Oliveira, V. S. (2020). Sobrevivência e perfil de resistência a antimicrobianos de isolados de Salmonella sp. em dejeto suíno armazenado. PUBVET, 14 (9), 1-7.

Oliver, W. T., \& Wells, J. E. (2015). Lysozyme as an alternative to growth promoting antibiotics in swine production. Journal of Animal Science and Biotechnology, 6(1), 35 .

Omonijo, F. A., Ni, L., Gong, J., Wang, Q., Lahaye, L., \& Yang, C. (2018). Essential oils as alternatives to antibiotics in swine production. Animal Nutrition, $4(2), 126-136$.

Quadros, C. L. (2018). Salmonella spp. isoladas em abatedouro frigorífico de suínos: resistência a sanitizantes e antimicrobianos. Dissertação de mestrado, Universidade de Passo Fundo, RS, Brasil.

Rodrigues, D. P., Reis, E. M. F. \& Costa, R. G. (2014). Relatório anual de atividades do Laboratório de Referência Nacional de Enteroinfecções Bacterianas. CGLAB/DEVEP/SVS.

Ryan, M. P., O’Dwyer, J., \& Adley, C. C. (2017). Evaluation of the Complex Nomenclature of the Clinically and Veterinary Significant Pathogen Salmonella. BioMed Research International, 2017, 1-6.

Santana, L. A., Pereira, S. O., Antônio, V. E., Castro, A. S. B., Miguel, P. S. B., \& Moreira, T. R. (2021). Febre tifoide: revisão para a prática clínica. Revista Científica UNIFAGOC-Saúde, 6(1), 73-83.

Silva, A. J. H., Anjos, C. P., Nogueira, L. S., Ribeiro, A. C. R., Fraga, E. G. S. (2018). Salmonella spp. Um Agente Patogênico Veiculado em Alimentos. Encontro de Extensão, Docência e Iniciação Científica (EEDIC). 5 (1), 1-7.

Subramaniam, M. D., \& Kim, I. H. (2015). Clays as dietary supplements for swine: A review. Journal of Animal Science and Biotechnology, 6(1).

Suiryanrayna, M. V. A. N., \& Ramana, J. V. (2015). A review of the effects of dietary organic acids fed to swine. Journal of Animal Science and Biotechnology, $6(1), 45$.

Suo, B., He, Y. \& Shi, X. (2010). A multiplex real-time polymerase chain reaction for simultaneous detection of Salmonella sp., Escherichia coli O157 and Listeria monocytogenes in meat products. Foodborne Pathogen Dis., v. 7, n. 6, p. 619-628.

Tang, K. L., Caffrey, N. P., Nóbrega, D. B., Cork, S. C., Ronksley, P. E., Barkema, H. W., \& Ghali, W. A. (2017). Restricting the use of antibiotics in foodproducing animals and its associations with antibiotic resistance in food-producing animals and human beings: A systematic review and meta-analysis. The Lancet Planetary Health, 1(8), 316-327.

Turci, C. R., Begotti, B. L. I. \& Merlini, S. L. (2013). Incidência de Salmonella sp. em carne de suíno comercializada no município de Umuarama - PR - Brasil. Enciclopédia Biosfera, 9 (16), 2748-2753.

Wang, Y. C., Chang, Y. C., Chuang, H. L., Chiu, C. C., Yeh, K. S., Chang, C. C., Hsuan, S. L. \& Chen, T. H. (2010). Antibiotic resistance, integrons and Salmonella genomic island 1 among Salmonella Schwarzengrund in broiler chicken and pig. African Journal of Microbiology Research, 4 (9), $677-681$.

World Health Organization (WHO). (2016). Global action plan on antimicrobial resistance. Geneva, Switzerland. 45p.

Yáñez, A. J., Valenzuela, K., Matzner, C., Olavarría, V., Figueroa, J., Avendaño-Herrera, R., \& Carcamo, J. G. (2013). Broth microdilution protocol for minimum inhibitory concentration (MIC) determinations of the intracellular salmonid pathogen Piscirickettsia salmonis to florfenicol and oxytetracycline. Journal of Fish Diseases, 37(5), 505-509.

Yang, B., Xi, M., Cui, S., Zhang, X., Shen, J., Sheng, M., Qu, D., Wang, X. \& Meng, J. (2012). Mutations in gyrase and topoisomerase genes associated with fluoroquinolone resistance in Salmonella serovars from retail meats. Food Research International, Barking, 45, 935-939. 